\title{
The endothelium as a target in pediatric OSA
}

\section{Leila Kheirandish-Gozal*}

Section of Pediatric Sleep Medicine, Department of Pediatrics, Pritzker School of Medicine, Biological Sciences Division, The University of Chicago, Chicago, IL, USA

\section{Edited by:}

Pierre-Charles Neuzeret, Lyon Neuroscience Research Center, France

\section{Reviewed by:}

Bindu M. Kutty, National Institute of Mental Health and Neurosciences, India

Shaikh Mohammed labal, King Saud University, Saudi Arabia

\section{*Correspondence.}

Leila Kheirandish-Gozal, Section of Pediatric Sleep Medicine, Department of Pediatrics, Pritzker School of

Medicine, The University of Chicago, 5841 S. Maryland Avenue/MC2117,

Chicago, IL 60637-1470, USA.

e-mail: Igozal@peds.bsd.uchicago.edu
Pediatric sleep disordered breathing has emerged in the last few decades as a highly prevalent condition by virtue of its major morbidities encompassing the central nervous, cardiovascular, and metabolic systems. In this context, improved understanding of the pathophysiological mechanisms underlying the cellular and organ injury and repair mechanisms, and the variance of the phenotype at any level of disease severity is all the more critical if appropriate personalized therapies are to be developed in the future. In this paper, the current evidence and hypothetical framework pointing to the endothelium as a primary cellular target for many of the morbidities of pediatric sleep apnea is reviewed, and particular emphasis on the recruitment of the endothelial cell lineage will be explored. It is hoped that this perspective will foster both expansion and acceleration of discovery efforts aiming to ultimately prevent the potentially lifelong consequences of sleep apnea during childhood.

Keywords: sleep, apnea, endothelium, progenitor cells, microparticles, hypertension, children

\section{INTRODUCTION}

The frequent presence of academic, behavioral and cognitive difficulties in children with sleep disordered breathing (SDB) has led to greatly increased awareness to this condition. In recent years, the cardiovascular system has been more systematically explored in the context of SDB, and the endothelium has emerged as a major, if not the major cellular target for injury in this disease. In this review, I will discuss the evidence linking pediatric sleep apnea to endothelial dysfunction.

\section{OSA IN CHILDREN}

Habitual snoring during sleep, the hallmark indicator of increased upper airway resistance, is an extremely frequent occurrence during early childhood, with a prevalence of up to $27 \%$ being reported (median 12\%; Hultcrantz et al., 1995; Ferreira et al., 2000; O’Brien et al., 2003; Rosen et al., 2003; Ersu et al., 2004; Kaditis et al., 2004; Montgomery-Downs et al., 2004; Urschitz et al., 2004; Montgomery-Downs and Gozal, 2006).

The spectrum of the condition termed "sleep disordered breathing" in children is difficult to define in a precise fashion because the cut-offs of what constitutes disease or not is still the subject of intense debate (Gozal and Kheirandish-Gozal, 2010; Spruyt et al., 2010). Notwithstanding of such elusive diagnostic criteria, obstructive sleep apnea (OSA) is most common in young children (pre-school and early school years) with a peak prevalence around 2-8 years, and subsequent declines in frequency (Corbo et al., 2001).In children, the two major pathophysiological determinants of OSA are enlargement of tonsils and adenoids and obesity. Indeed, the rather accelerated increase over the last two decades in the prevalence of pediatric obesity has led to substantial changes in the cross sectional demographic and anthropometric characteristics of the children being referred for evaluation of habitual snoring. For example, while $<15 \%$ of all symptomatic habitually snoring children were obese (i.e., body-mass index $z$ score $>1.57$ ) in the early 1990's, $>50 \%$ fulfilled such criteria among all clinical referrals for suspected OSA in the last 2-3 years at our Sleep Center (Gozal et al., 2006). A substantial body of evidence has accumulated in the last decades to rather conclusively suggest that $\mathrm{SDB}$ can lead to substantial morbidities affecting CNS, cardiovascular and metabolic systems, and somatic growth, ultimately leading to significant reductions in the quality of life (Dayyat et al., 2007) Furthermore, it is likely that the concomitant presence of obesity and OSA will potentiate such morbidities, suggesting that they may be targeting similar cellular substrates whose dysfunction may underlie the end-organ morbidities seen in SDB (Bhattacharjee et al., 2011; Spruyt and Gozal, 2012).

\section{CARDIOVASCULAR MORBIDITY OF PEDIATRIC OSA}

Similar to adults, OSA in children has now been associated with an increased risk for cardiovascular morbidities, albeit with reduced phenotypic severity, most likely the corollary of the better compensatory vascular capacitance in children. For example, increased prevalence of altered blood pressure regulation (Amin et al., 2004), systemic hypertension, (Marcus et al., 1998; Enright et al., 2003; Kohyama et al., 2003), and changes in left ventricular geometry, (Amin et al., 2002, 2005), have all now been described in children with OSA, and appear to be severity-dependent (Aljadeff et al., 1997). The mechanisms mediating cardiac and blood pressure changes are most likely associated with the increases in sympathetic activity and reactivity that progressively develop in the context of OSA (Baharav et al., 1999; O'Brien and Gozal, 2005; Hakim et al., 2012). In addition, recent evidence supports the assumption of potential endothelial dysfunction in children with OSA, as evidenced by increases in the circulating levels of several adhesion molecules (O’Brien et al., 2006). Parenthetically, the endothelial dysfunction associated with OSA is most likely 
the result of initiation and propagation of oxidative stress and inflammatory responses within the microvasculature (Hansson, 2005).

For example, C-reactive protein, which has been traditionally linked to increased risk for cardiovascular disease even if such assumption has been recently challenged, (Elias-Smale et al., 2007; Kovacs et al., 2007) provides a good systemic marker for the presence of inflammation. In a series of recent studies, plasma concentrations of C-reactive protein were elevated in a severitydependent fashion among children and adolescents with OSA, even after correction for body-mass index (Tauman et al., 2004; Larkin et al., 2005; Kheirandish-Gozal et al., 2006). Only one study by Kaditis et al. (2005) failed to identify these relationships in a study of Greek children.

Therefore, it is highly probable that OSA will elicit a variable, yet significant systemic inflammatory response, which in turn may initiate and propagate atherogenetic mechanisms. In support of this assumption, three major recent studies from our laboratory revealed the following:

(1) IL-6 levels were higher and IL-10 plasma levels were lower in non-obese children with OSA and returned to control levels after treatment with surgical tonsillectomy and adenoidectomy (T\&A; Gozal et al., 2008b).

(2) Evidence for flow-dependent reperfusion abnormalities indicative of endothelial dysfunction was identified in nonobese children with OSA, and was reversed in most cases after adenotonsillectomy (T\&A; Gozal et al., 2007; see below).

(3) Endothelial dysfunction and neurocognitive deficits are highly overlapping phenomena in pediatric OSA. Thus, both of these morbid consequences may share similar pathogenetic mechanisms involving the endothelium as the primary process driving neuronal dysfunction (Gozal et al., 2010).

In the context of the epidemic of childhood obesity, we have also recently shown that obesity alone elicits endothelial dysfunction, and that obesity and OSA will interact and potentiate the adverse functional consequences on the endothelium (Kheirandish-Gozal et al., 2006; Gozal et al., 2008a).

This is a particularly important issue, since the presence of early cardiovascular risk factors in childhood has been linked to decreased survival and increased cardiovascular morbidity later in life (Berenson et al., 2005).

\section{ALTERATIONS IN ENDOTHELIAL FUNCTION IN PEDIATRIC OSA}

In addition to autonomic nervous system changes, the systemic inflammatory pathways activated in the presence of OSA could induce functional and structural disruption of the endothelium (Figure 1). Indeed, reductions in brachial artery flow-mediated dilation, a surrogate marker of endothelial functional integrity, have been reported in adults with OSA (Kato et al., 2000; Nieto et al., 2004; Oflaz et al., 2006) and were improved after treatment with CPAP (Ip et al., 2004; Ohike et al., 2005; Lattimore et al., 2006).

Similar findings were also communicated on younger adult patients with OSA who were free of any known cardiovascular involvement, and as previously shown, CPAP treatment resulted in reversal of endothelial dysfunction (Itzhaki and Wertheimer, 1997; Itzhaki et al., 2007).

Endothelial functional changes have also emerged as a frequent complication of obesity (Suheyl et al., 2005; Bhattacharjee et al., 2010) and diabetes (Valle Jimenez et al., 2007), and these are important issues considering the increased prevalence of OSA in obese children (Tauman and Gozal, 2006; Kaditis et al., 2008; Verhulst et al., 2008, 2009; Bixler et al., 2009; Dayyat et al., 2009) and also the potential interactions between obesity and OSA to amplify end-organ dysfunction (Gozal and Kheirandish-Gozal, 2009; Kim et al., 2010).

I am only aware of a paucity of studies, all of which originated from our laboratory that have thus far explored whether OSA adversely impacts on endothelial function in children. The initial study explored endothelial function in 26 non-obese children with OSA using a novel approach to the post-occlusion hyperemic response test. In this study, endothelial function was significantly impaired when compared to healthy controls. Furthermore, significant improvements or complete normalization of endothelial function occurred 6 months after treatment of OSA with adenotonsillectomy in the majority of the children. However, the presence of a strong family history of early onset cardiovascular disease in six of the 26 children was associated with no improvements in endothelial function after adenotonsillectomy (Gozal et al., 2007).

This observation, if repeated in other cohorts, would position OSA not only as a major trigger for disruption of vascular function in genetically predisposed children, but also for initiating a cascade of vascular events in these children that would be more difficult if not impossible to reverse, leading to earlier onset and increased severity of cardiovascular diseases during adulthood. In a subsequent study, we found that obesity and OSA appear to potentiate the magnitude of endothelial damage possibly via activation of systemic inflammatory pathways, as evidenced by MRP 8/14 and CRP levels (Kim et al., 2010).

\section{ENDOTHELIAL PROGENITOR CELLS}

Although in pediatric OSA significant increases in established soluble molecules reflecting alterations of the main regulatory functions of the endothelium such as inflammation, hemostasis, or permeability are found, these markers have been somewhat disappointing by their lack of specificity and clinical relevance at the individual level. The capacity of the adherent endothelium to undergo cellular alterations has provided insights on the endothelium as being a dynamic tissue in equilibrium with a circulating compartment reflecting both lesion and regeneration of the vascular tree. This endothelial-derived compartment has led to delineate a third group of cellular markers, corresponding to circulating endothelial cells (CEC) and endothelial-derived microparticles (EMP) released from the injured vessels and also progenitors endothelial progenitor cells (EPC).

Described 30 years ago as inert "cellular dust" cell-derived microparticles (MPs) are considered to be microvesicles $(0.05-$ $1 \mu \mathrm{m}$ ) released through the process of exocytic budding of the plasma membrane following stimulation of different cell types (Hugel et al., 2005; Nomura et al., 2008). 


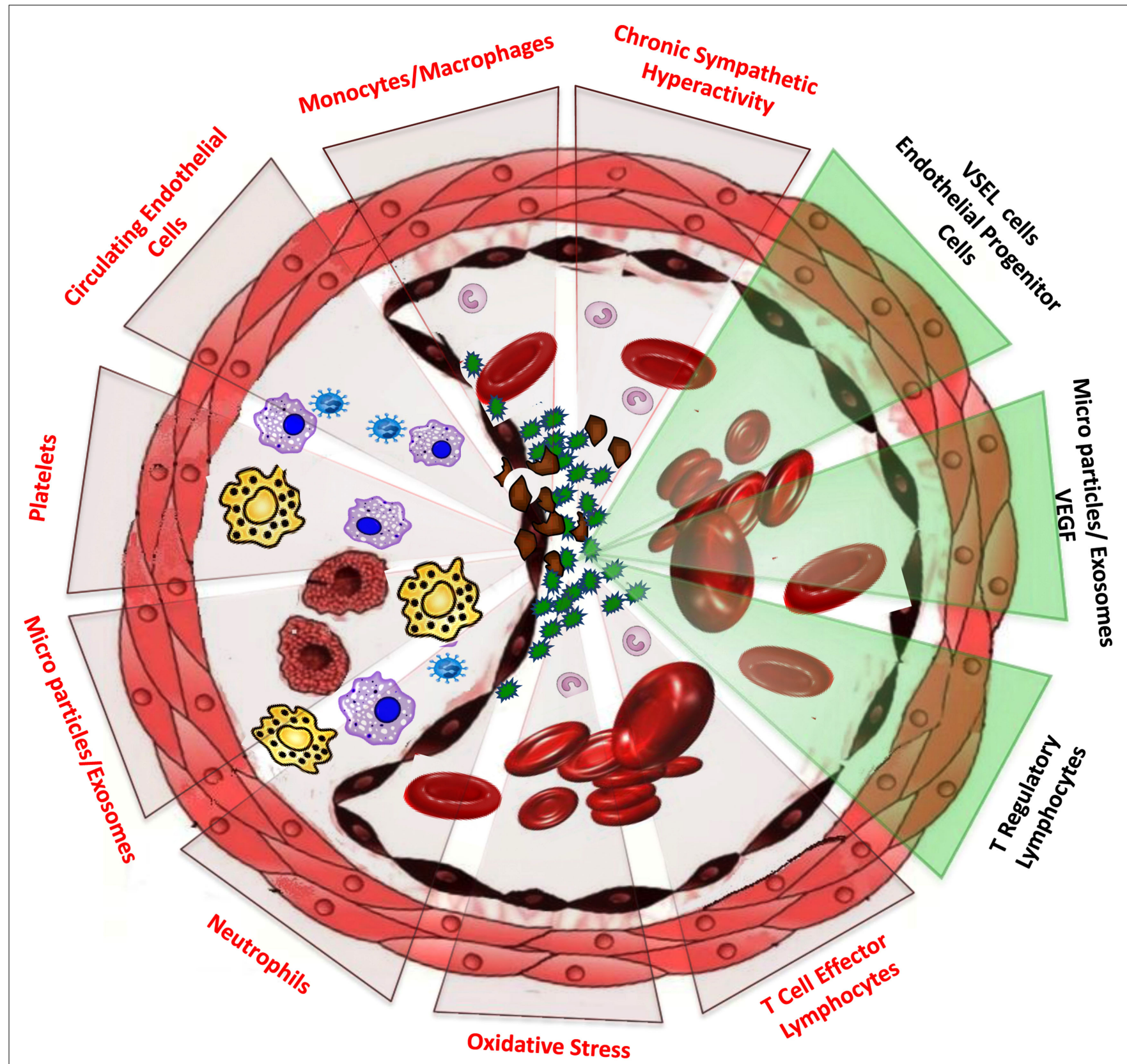

FIGURE 1 | Schematic diagram displaying the activation of injurious pathways in the vasculature as related to OSA. The activation of these pathways coordinates then a variety of cascades leading to reduced nitric oxide bioavailability, endothelial damage and dysfunction, shedding of apoptotic endothelial cells, and migration of monocytes and macrophages to form foam cells and promote atherosclerosis. In parallel with such events, release of a variety of chemokines and pro-angiogenic agents, such as VEGF may be prompted by some subsets of cell-derived microparticles or exosomes, and may lead to recruitment, migration, and homing to the damaged endothelium of multiple sub-populations of bone marrow resident stem cells that have the potential to repair the injured endothelium and either mitigate or induce a regain of vascular function (green background triangles).
There are two well-known cellular processes that can lead to the formation of MPs: chemical and physical cell activation (by agonists or shear stress, respectively), and apoptosis. However, the mechanisms that take place during MP formation are not completely elucidated. An asymmetric distribution of phospholipids is generated during membrane biogenesis; this asymmetry is lost after cell stimulation, and several studies suggest that this is necessary for MP formation. In normal persons, EMPs represent a minority of total circulating MP. Flow cytometry is the most widely used method to characterize EMPs, but the pro-coagulant function of EMP can also be measured using functional assays (based on coagulation activation by MP derived phospholipids and/or TF), and these two complementary approaches have been recently reviewed in a forum aiming to establish standards in measurement 
techniques and reporting methods (Jy et al., 2004; Freyssinet and Dignat-George, 2005).

Using state-of-the-art consensus approaches we have provided compelling support to the notion that MP's are increased in pediatric OSA (Kim et al., 2011), whereby we showed that endothelial MPs and endothelial progenitor MPs, leukocyte MPs, and platelet MPs levels are all significantly different according to severity of OSA in children. Furthermore, platelet-derived MPs emerge as independent contributors to the vascular dysfunction associated with OSA in children and may account for increased risk for altered endothelial function (Kim et al., 2011).

Current understanding supports the view that CEC are mature cells shed from the vessel wall in response to injury (Blann et al., 2005). These cells present a heterogeneous size (from 10 to 50 micron), express endothelial markers (von Willebrand factor [vWF], CD31, CD144) but are negative for leukocyte markers. In contrast to EPC, they do not express immature markers such as $\mathrm{CD} 133$, and do not give rise to cell colonies with a high proliferative potential. Due to the extreme scarcity of CEC in peripheral blood, an important step in their identification has been the development of sensitive technologies for the detection of rare events based on the immunolabeling with monoclonal antibodies to novel endothelial antigens (George et al., 1991; Woywodt et al., 2006). In 1992, an antibody recognizing the CD146 antigen combined with an immuno-magnetic separation assay allowed the immunological characterization of CEC in the peripheral blood of patients submitted to coronary angioplasty chosen as a model of vascular injury. The marked elevation of CEC number found after angioplasty, confirmed that they result from endothelial trauma triggered by the catheter procedure itself (George et al., 1992).

Thus, CEC are sensitive indicators of endothelial cell damage, and could provide important insights into OSA-induced vascular dysfunction. We are currently unaware of any published studies on CEC in pediatric OSA.

In 1997, Asahara et al. (1997) initially reported that that purified CD34 positive hematopoietic progenitor cells from adults were able to differentiate ex vivo to an endothelial cell phenotype .

These cells were named "endothelial progenitor cells" (EPC), and showed expression of various endothelial markers (Asahara et al., 1997). Circulating EPC have emerged as an important marker associated with cardiovascular risk profile and physical fitness (Vasa et al., 2001; Werner et al., 2005).

Endothelial progenitor cells originate from bone marrow stem cells through a chemokine-dependent gradient involving stromal differentiation factor 1 (SDF1; also known as CXC chemokine ligans 12) and its ligand receptor CXC chemokine receptor4 (CXCR4), and such factors appear to be determined not only by SDF1 gene variation but also by the response to specific stimuli

\section{REFERENCES}

Aiuti, A., Webb, I. J., Bleul, C., Springer, T., and Gutierrez-Ramos, J. C. (1997). The chemokine SDF1 is a chemoattractant for human $\mathrm{CD} 34+$ hematopoietic progenitor cells and provides a new mechanism to explain the mobilization of $\mathrm{CD} 34+$ progenitors to peripheral blood. J. Exp. Med. 185, 111-120.

Aljadeff, G., Gozal, D., Schechtman, V. L., Burrell, B., Harper, R. M., and Ward, S. L. (1997). Heart rate variability in children with obstructive sleep apnea. Sleep 20,151-157.

Amin, R. S., Carroll, J. L., Jeffries, J. L., Grone, C., Bean, J. A., Chini,

such as hypoxia (Aiuti et al., 1997; Benboubker et al., 2001; Moore et al., 2001; De Falco et al., 2004; Dimmeler and Zeiher, 2004; Doyle et al., 2006; Werner and Nickenig, 2007; Xiao et al., 2007).

Endothelial progenitor cells are involved in neovessel formation and endothelial regeneration, with reduced levels and functional impairment of EPCs being correlated with the presence of coronary artery disease (Benboubker et al., 2001; De Falco et al., 2004).

Recent work by Jelic and colleagues has shown that OSA in adult patients is not only associated with abnormal endothelial function and increased inflammatory and oxidative stress responses, but is also accompanied by reduced numbers of circulating EPC. Furthermore, treatment of OSA with CPAP resulted in improvement of endothelial function and concomitant increases in the number of circulating EPC (Jelic et al., 2008).

As mentioned above, we have reported on the presence of endothelial dysfunction on non-obese children with OSA (Gozal et al., 2007) and that effective treatment of OSA resulted in reversal of endothelial dysfunction in approximately $80 \%$ of these children. While genetic predisposition of premature cardiovascular disease could be a factor associated in the lack of improved endothelial function in these children (Gozal et al., 2007) the possibility exists that the underlying EPC and SDF1 responses to OSA may also contribute to endothelial repair. Furthermore, a substantial degree of variability is present in the time to peak reperfusion after a $60 \mathrm{~s}-$ brachial occlusion maneuver in children with OSA, suggesting that the magnitude of endothelial dysfunction may be explained at least in part by the number of circulating EPC (Kheirandish-Gozal et al., 2010).

\section{SUMMARY}

Taken together, a causative link between OSA and endothelial dysfunction in children is likely, and deserves further exploration including identification of mechanisms underlying this potential morbidity. Based on aforementioned considerations, delineation of such mechanisms will need to account for processes that mediate injury and also for those that promote vascular repair and functional integrity (Figure 1). Although the deleterious effects of OSA on such systems may be reversed by early diagnosis and treatment, the epidemic of childhood obesity is likely to aggravate this problem, and therefore, improved techniques aiming to establish the endothelial phenotype in the context of clinical practice need to be developed, such as to enable risk assessment and optimal interventions, aiming to prevent the adverse consequences of such alterations on morbidity and mortality later in life.

\section{ACKNOWLEDGMENTS}

Leila Kheirandish-Gozal is supported by NIH grant K12 HL090003.

B., Bokulic, R., and Daniels, S. R. (2004). Twenty-four-hour ambulatory blood pressure in children with sleep-disordered breathing. Am. J. Respir. Crit. Care Med. 169, 950-956. Amin, R. S., Kimball, T. R., Bean, J. A., Jeffries, J. L., Willging, J. P., Cotton, R. T., Witt, S. A., Glascock, B. J., and Daniels, S. R. (2002). Left ventricular hypertrophy and abnormal ventricular geometry in children and adolescents with obstructive sleep apnea. Am. J. Respir. Crit. Care. Med. 165, 1395-1399.

Amin, R. S., Kimball, T. R., Kalra, M., Jeffries, J. L., Carroll, J. L., Bean, J. A., Witt, S. A., Glascock, B. J., and Daniels, S. R. (2005). Left 
ventricular function in children with sleep-disordered breathing. Am. J. Cardiol. 95, 801-804.

Asahara, T., Murohara, T., Sullivan, A., Silver, M., van der Zee, R., Li, T., Witzenbichler, B., Schatteman, G., and Isner, J. M. (1997). Isolation of putative progenitor endothelial cells for angiogenesis. Science 140,408417.

Baharav, A., Kotagal, S., Rubin, B. K., Pratt, J., and Akselrod, S. (1999). Autonomic cardiovascular control in children with obstructive sleep apnea. Clin. Auton. Res. 9, 345-351.

Benboubker, L., Watier, H., Carion, A., Georget, M. T., Desbois, I., Colombat, P., Bardos, P., Binet, C., and Domenech, J. (2001). Association between the SDF1-39A allele and high levels of CD34(+) progenitor cells mobilized into peripheral blood in humans. Br. J. Haematol. 113, 247-250.

Berenson, G. S., Srnivasan, S. R., and Bogalusa Heart Study Group. (2005). Cardiovascular risk factors in youth with implications for aging: the Bogalusa Heart Study. Neurobiol. Aging 26, 303-307.

Bhattacharjee, R., Alotaibi, W. H., Kheirandish-Gozal, L., Capdevila, O. S., and Gozal, D. (2010). Endothelial dysfunction in obese non-hypertensive children without evidence of sleep disordered breathing. BMC Pediatr. 10, 8 . doi:10.1186/1471-2431-10-8

Bhattacharjee, R., Kim, J., KheirandishGozal, L., and Gozal, D. (2011). Obesity and obstructive sleep apnea syndrome in children: a tale of inflammatory cascades. Pediatr. Pulmonol. $46,313-323$

Bixler, E. O., Vgontzas, A. N., Lin, H. M., Liao, D., Calhoun, S., Vela-Bueno, A., Fedok, F., Vlasic, V., and Graff, G. (2009). Sleep disordered breathing in children in a general population sample: prevalence and risk factors. Sleep 32, 731-736.

Blann, A. D., Woywodt, A., Bertolini, F., Bull, T. M., Buyon, J. P., Clancy, R. M., Haubitz, M., Hebbel, R. P., Lip, G. Y., and Mancuso, P. (2005). Circulating endothelial cells. Biomarker of vascular disease. Thromb. Haemost. 93, 228-235.

Corbo, G. M., Forastiere, F., Agabiti, N., Pistelli, R., Dell'Orco, V., Perucci, C. A., and Valente, S. (2001). Snoring in 9- to 15-year-old children: risk factors and clinical relevance. Pediatrics 108, 1149-1154.

Dayyat, E., Kheirandish-Gozal, L., and Gozal, D. (2007). Childhood obstructive sleep apnea: one or two distinct disease entities? Sleep. Med. Clin. 2, 433-444.

Dayyat, E., Kheirandish-Gozal, L., Sans Capdevila, O., Maarafeya, M. M., and Gozal, D. (2009). Obstructive sleep apnea in children: relative contributions of body mass index and adenotonsillar hypertrophy. Chest 136, 137-144.

De Falco, E., Porcelli, D., Torella, A. R., Straino, S., Iachininoto, M. G., Orlandi, A., Truffa, S., Biglioli, P., Napolitano, M., Capogrossi, M. C., and Pesce, M. (2004). SDF-1 involvement in endothelial phenotype and ischemia-induced recruitment of bone marrow progenitor cells. Blood 104, 3472-3482.

Dimmeler, S., and Zeiher, A. M. (2004). Vascular repair by circulating endothelial progenitor cells: the missing link in atherosclerosis? $\mathrm{J}$. Mol. Med. 82, 671-677.

Doyle, B., Metharom, P., and Caplice, N. M. (2006). Endothelial progenitor cells. Endothelium 13, 403-410.

Elias-Smale, S. E., Kardys, I., Oudkerk, M., Hofman, A., and Witteman, J. C. (2007). C-reactive protein is related to extent and progression of coronary and extra-coronary atherosclerosis; results from the Rotterdam study. Atherosclerosis 195, e195e202.

Enright, P. L., Goodwin, J. L., Sherrill, D. L., Quan, J. R., and Quan, S. F. (2003). Blood pressure elevation associated with sleep-related breathing disorder in a community sample of white and Hispanic children: the Tucson Children's Assessment of Sleep Apnea study. Arch. Pediatr. Adolesc. Med. 157, 901-904.

Ersu, R., Arman, A. R., Save, D., Karadag, B., Karakoc, F., Berkem, M., and Dagli, E. (2004). Prevalence of snoring and symptoms of sleep-disordered breathing in primary school children in Istanbul. Chest 126, 19-24.

Ferreira, A. M., Clemente, V., Gozal, D., Gomes, A., Pissarra, C., César, H., Coelho, I., Silva, C. F., and Azevedo, M. H. (2000). Snoring in Portuguese primary school children. Pediatrics 106, E64.

Freyssinet, J. M., and Dignat-George, F. (2005). More on: Measuring circulating cell-derived microparticles. $J$. Thromb. Haemost. 3, 613-614.

George, F., Brisson, C., Poncelet, P., Laurent, J. C., Massot, O., Arnoux, D., Ambrosi, P., Klein-Soyer, C., Cazenave, J. P., and Sampol, J. (1992). Rapid isolation of human endothelial cells from whole blood using S-Endol monoclonal antibody coupled to immuno-magnetic beads: demonstration of endothelial injury after angioplasty. Thromb. Haemost. 67, 147-153.

George, F., Poncelet, P., Laurent, J. C., Massot, O., Arnoux, D., Lequeux, N. Ambrosi, P., Chicheportiche, C., and Sampol, J. (1991). Cytofluorometric detection of human endothelia cells in whole blood using S-Endo 1 monoclonal antibody. J. Immunol. Methods 139, 65-75.

Gozal, D., Capdevila, O. S., and Kheirandish-Gozal, L. (2008a). Metabolic alterations and systemic inflammation in obstructive sleep apnea among nonobese and obese prepubertal children. Am. J. Respir. Crit. Care. Med. 177, 1142-1149.

Gozal, D., Serpero, L. D., Sans Capdevila, O., and Kheirandish-Gozal, L. (2008b). Systemic inflammation in non-obese children with obstructive sleep apnea. Sleep. Med. 9, 254-259.

Gozal, D., and Kheirandish-Gozal, L. (2010). New approaches to the diagnosis of sleep-disordered breathing in children. Sleep Med. 11, 708-713.

Gozal, D., and Kheirandish-Gozal, L. (2009). Obesity and excessive daytime sleepiness in pre-pubertal children with obstructive sleep apnea. Pediatrics 123, 13-18.

Gozal, D., Kheirandish-Gozal, L., Bhattacharjee, R., and Spruyt, K. (2010). Neurocognitive and endothelial dysfunction in children with obstructive sleep apnea. Pediatrics 126, e11611167.

Gozal, D., Kheirandish-Gozal, L., Serpero, L. D., Sans Capdevila, O., and Dayyat, E. (2007). Obstructive sleep apnea and endothelial function in school-aged non-obese children: effect of adenotonsillectomy. Circulation 116, 2307-2314.

Gozal, D., Simakajornboon, N., Holbrook, C. R., Crabtree, V. M., Krishna, J., Jones, J. H., and Kheirandish-Gozal, L. (2006). Secular trends in obesity and parentally reported daytime sleepiness among children referred to a pediatric sleep center for snoring and suspected sleep-disordered breathing (SDB). Sleep, 29, A74.

Hakim, F., Gozal, D., and KheirandishGozal, L. (2012). Sympathetic and catecholaminergic alterations in sleep apnea with particular emphasis on children. Front. Neurol. 3:7. doi:10.3389/fneur.2012.00007

Hansson, G. K. (2005). Inflammation, atherosclerosis, and coronary artery disease. N. Engl. J. Med. 352, 1685-1695.

Hugel, B., Martínez, M. C., Kunzelmann, C., and Freyssinet, J. M. (2005). Membrane microparticles: two sides of the coin. Physiology, 20, $22-27$.

Hultcrantz, E., Lofstrand-Tidestrom, B., and Ahlquist-Rastad, J. (1995). The epidemiology of sleep related breathing disorder in children. Int. J. Pediatr. Otorhinolaryngol. 32(Suppl.), S63-S66.

Ip, M. S., Tse, H. F., Lam, B., Tsang, K. W., and Lam, W. K. (2004). Endothelial function in obstructive sleep apnea and response to treatment. Am. J. Respir. Crit. Care. Med. 169, 348-353.

Itzhaki, S., Dorchin, H., Clark, G., Lavie, L., Lavie, P., and Pillar, G. (2007). The effects of 1-year treatment with a herbst mandibular advancement splint on obstructive sleep apnea, oxidative stress, and endothelial function. Chest 131, 740-749.

Itzhaki, S., and Wertheimer, E. (1997). Metabolism of adipose tissue in vitro: nutritional factors and effect of insulin. Endocrinology 61, $72-78$.

Jelic, S., Padeletti, M., Kawut, S. M., Higgins, C., Canfield, S. M., Onat, D., Colombo, P. C., Basner, R. C., Factor, P., and LeJemtel, T. H. (2008). Inflammation, oxidative stress, and repair capacity of the vascular endothelium in obstructive sleep apnea. Circulation 117, 2270-2278.

Jy, W., Horstman, L. L., Jimenez, J. J., Ahn, Y. S., Biró, E., Nieuwland, R., Sturk, A., Dignat-George, F., Sabatier, F., Camoin-Jau, L., Sampol, J., Hugel, B., Zobairi, F., Freyssinet, J. M., Nomura, S., Shet, A. S., Key, N. S., and Hebbel, R. P. (2004). Measuring circulating cell-derived microparticles. J. Thromb. Haemost. 2, 1842-1851.

Kaditis, A. G., Alexopoulos, E. I., Hatzi, F., Karadonta, I., Chaidas, K., Gourgoulianis, K., Zintzaras, E., and Syrogiannopoulos, G. A. (2008). Adiposity in relation to age as predictor of severity of sleep apnea in children with snoring. Sleep Breath. 12, 25-31.

Kaditis, A. G., Alexopoulos, E. I., Kalampouka, E., Kostadima, E., Germenis, A., Zintzaras, E., Gourgoulianis, K. (2005). Morning levels of C-reactive protein in children with obstructive sleep-disordered breathing. Am J. Respir. Crit. Care. Med. 171, 282-286.

Kaditis, A. G., Finder, J., Alexopoulos, E. I., Starantzis, K., Tanou, K., Gampeta, S., Agorogiannis, E., Christodoulou, S., Pantazidou, A., Gourgoulianis, K., and Molyvdas, P. A. (2004). Sleep-disordered 
breathing in 3,680 Greek children. Pediatr. Pulmonol. 37, 499-509.

Kato, M., Roberts-Thomson, P., Phillips, B. G., Haynes, W. G., Winnicki, M., Accurso, V., and Somers, V. K. (2000). Impairment of endothelium-dependent vasodilation of resistance vessels in patients with obstructive sleep apnea. Circulation 102, 2607-2610.

Kheirandish-Gozal, L., Bhattacharjee, R., Kim, J., Clair, H. B., and Gozal, D. (2010). Endothelial progenitor cells and vascular dysfunction in children with obstructive sleep apnea. Am. J. Respir. Crit. Care. Med. 182, 92-97.

Kheirandish-Gozal, L., Capdevila, O. S., Tauman, R., and Gozal, D. (2006). Plasma C-reactive protein in nonobese children with obstructive sleep apnea before and after adenotonsillectomy. J. Clin. Sleep. Med. 2, 301-304.

Kim, J., Bhattacharjee, R., KheirandishGozal, L., Spruyt, K., and Gozal, D. (2011). Circulating microparticles in children with sleep disordered breathing. Chest 140, 408-417.

Kim, J., Bhattacharjee, R., Snow, A. B., Capdevila, O. S., Kheirandish-Gozal, L., and Gozal, D. (2010). Myeloidrelated protein $8 / 14$ levels in children with obstructive sleep apnoea. Eur. Respir. J. 35, 843-850.

Kohyama, J., Ohinata, J. S., and Hasegawa, T. (2003). Blood pressure in sleep disordered breathing. Arch. Dis. Child. 88, 139-142.

Kovacs, A., Tornvall, P., Nilsson, R., Tegner, J., Hamsten, A., and Bjorkegren, J. (2007). Human C-reactive protein slows atherosclerosis development in a mouse model with human-like hypercholesterolemia. Proc. Natl. Acad. Sci. U.S.A. 104, 13768-13773.

Larkin, E. K., Rosen, C. L., Kirchner, H. L., Storfer-Isser, A., Emancipator, J. L., Johnson, N. L., Zambito, A. M., Tracy, R. P., Jenny, N. S., and Redline, S. (2005). Variation of C-reactive protein levels in adolescents: association with sleep disordered breathing and sleep duration. Circulation 111, 1978-1984.

Lattimore, J. L., Wilcox, I., Skilton, M., Langenfeld, M.,and Celermajer, D. S. (2006). Treatment of obstructive sleep apnoea leads to improved microvascular endothelial function in the systemic circulation. Thorax 61, 491-495.

Marcus, C. L., Greene, M. G., and Carroll, J. L. (1998). Blood pressure in children with obstructive sleep apnea. Am. J. Respir. Crit. Care. Med. 157(Pt 1), 1098-1103.

Montgomery-Downs, H. E., and Gozal, D. (2006). Sleep habits and risk factors for sleep-disordered breathing in infants and young toddlers in Louisville, Kentucky. Sleep Med. 7, 211-219.

Montgomery-Downs, H. E., O'Brien, L. M., Holbrook, C. R., and Gozal, D. (2004). Snoring and sleepdisordered breathing in young children: subjective and objective correlates. Sleep 27, 87-94.

Moore, M. A., Hattori, K., Heissig, B., Shieh, J. H., Dias, S., Crystal, R. G., and Rafii, S. (2001). Mobilization of endothelial and hematopoietic stem and progenitor cells by adenovectormediated elevation of serum levels of SDF-1, VEGF, and angiopoietin1. Ann. N. Y. Acad. Sci. 938, 36-45; discussion 45-37.

Nieto, F. J., Herrington, D. M., Redline, S., Benjamin, E. J., and Robbins, J. A. (2004). Sleep apnea and markers of vascular endothelial function in a large community sample of older adults. Am. J. Respir. Crit. Care. Med.169, 354-360.

Nomura, S., Ozaki, Y., and Ikeda, Y. (2008). Function and role of microparticles in various clinical settings. Thromb. Res.123, 8-23.

O'Brien, L. M., and Gozal, D. (2005). Autonomic dysfunction in children with sleep-disordered breathing. Sleep 28, 747-752.

O’Brien, L. M., Holbrook, C. R., Mervis, C. B., Klaus, C. J., Bruner, J. L., Raffield, T. J., Rutherford, J., Mehl, R. C., Wang, M., Tuell, A., Hume, B. C., and Gozal, D. (2003). Sleep and neurobehavioral characteristics of 5- to 7-year-old children with parentally reported symptoms of attention-deficit/hyperactivity

disorder. Pediatrics 111, 554-563.

O'Brien, L. M., Serpero, L. D., Tauman, R., and Gozal, D. (2006). Plasma adhesion molecules in children with sleep-disordered breathing. Chest 129, 947-953.

Oflaz, H., Cuhadaroglu, C., Pamukcu, B., Meric, M., Ece, T., Kasikcioglu, E., and Koylan, N. (2006). Endothelial function in patients with obstructive sleep apnea syndrome but without hypertension. Respiration 73, 751-756.

Ohike, Y., Kozaki, K., Iijima, K., Eto, M., Kojima, T., Ohga, E., Santa, T., Imai, K., Hashimoto, M., Yoshizumi,
M., and Ouchi, Y. (2005). Amelioration of vascular endothelial dysfunction in obstructive sleep apnea syndrome by nasal continuous positive airway pressure possible involvement of nitric oxide and asymmetric NG, NG-dimethylarginine. Circ. J. 69, 221-226.

Rosen, C. L., Larkin, E. K., Kirchner, H. L., Emancipator, J. L., Bivins, S. F., Surovec, S. A., Martin, R. J., and Redline, S. (2003). Prevalence and risk factors for sleep-disordered breathing in 8- tol1-year-old children: association with race and prematurity. J. Pediatr. 142, 383-389.

Spruyt, K., and Gozal, D. (2012). A mediation model linking body weight, cognition, and sleepdisordered breathing. Am. J. Respir. Crit. Care. Med. 185, 199-205.

Spruyt, K., Verleye, G., and Gozal, D. (2010). Unbiased categorical classification of pediatric sleep disordered breathing. Sleep 33, 1341-1347.

Suheyl, Ezgu. F., Hasanoglu, A., Tumer L., Ozbay, F., Aybay, C., and Gunduz, M. (2005). Endothelial activation and inflammation in prepubertal obese Turkish children. Metabolism 54, 1384-1389.

Tauman, R., and Gozal, D. (2006). Obesity and obstructive sleep apnea in children. Paediatr. Respir. Rev. 7, 247-259.

Tauman, R., Ivanenko, A., O'Brien, L. M., and Gozal, D. (2004). Plasma C-reactive protein levels among children with sleep-disordered breathing. Pediatrics 113, e564-e569.

Urschitz, M. S., Guenther, A., Eitner, S., Urschitz-Duprat, P. M., Schlaud, M., Ipsiroglu, O. S., and Poets, C. F. (2004). Risk factors and natural history of habitual snoring. Chest 126, 790-800.

Valle Jimenez, M., Estepa, R. M., Camacho, R. M., Estrada, R. C., Luna, F. G., and Guitarte, F. B. (2007) Endothelial dysfunction is related to insulin resistance and inflammatory biomarker levels in obese prepubertal children. Eur. J. Endocrinol. 156 497-502.

Vasa, M., Fichtlscherer, S., Aicher, A. Adler, K., Urbich, C., Martin, H., Zeiher, A. M., and Dimmeler, S. (2001). Number and migratory activity of circulating endothelial progenitor cells inversely correlate with risk factors for coronary artery disease. Circ. Res. 89, e1-e7.

Verhulst, S. L., Rooman, R., Van Gaal, L., De Backer, W., and Desager, K.
(2009). Is sleep-disordered breathing an additional risk factor for the metabolic syndrome in obese children and adolescents? Int. J. Obes. (Lond). 33, 8-13.

Verhulst, S. L., Van, Gaal. L., De Backer, W., and Desager, K. (2008). The prevalence, anatomical correlates and treatment of sleep-disordered breathing in obese children and adolescents. Sleep. Med. Rev. 12, 339-346.

Werner, N., Kosiol, S., Schiegl, T., Ahlers, P., Walenta, K., Link, A., Böhm, M., and Nickenig, G. (2005). Circulating endothelial progenitor cells and cardiovascular outcomes. N. Engl. J. Med. 353, 999-1007.

Werner, N., and Nickenig, G. (2007). Endothelial progenitor cells in health and atherosclerotic disease. Ann. Med. 39, 82-90.

Woywodt, A., Blann, A. D., Kirsch, T., Erdbruegger, U., Banzet, N., Haubitz, M., and Dignat-George, F. (2006). Isolation and enumeration of circulating endothelial cells by immunomagnetic isolation: proposal of a definition and a consensus protocol. J. Thromb. Haemost. 4, 671-677.

Xiao, Q., Kiechl, S., Patel, S., Oberhollenzer, F., Weger, S., Mayr, A., Metzler, B., Reindl, M., Hu, Y., Willeit, J., and $\mathrm{Xu}, \mathrm{Q}$. (2007). Endothelial progenitor cells, cardiovascular risk factors, cytokine levels and atherosclerosisresults from a large populationbased study. PLoS. One. 2:e975. doi:10.1371/journal.pone.0000975

Conflict of Interest Statement: The author declares that the research was conducted in the absence of any commercial or financial relationships that could be construed as a potential conflict of interest.

Received: 28 April 2012; accepted: 22 May 2012; published online: 11 June 2012.

Citation: Kheirandish-Gozal L (2012) The endothelium as a target in pediatric OSA. Front. Neur. 3:92. doi: 10.3389/fneur.2012.00092

This article was submitted to Frontiers in Sleep and Chronobiology, a specialty of Frontiers in Neurology.

Copyright () 2012 Kheirandish-Gozal. This is an open-access article distributed under the terms of the Creative Commons Attribution Non Commercial License, which permits non-commercial use, distribution, and reproduction in other forums, provided the original authors and source are credited. 